\title{
Arbor
}

\section{El Centro de Investigación del Cáncer (CSIC-Universidad de Salamanca): un ejemplo de cultura científica}

\section{Almudena Timón}

Arbor CLXXIII, 683-684 (Noviembre-Diciembre 2002), 653-668 pp.

Tradicionalmente en España el concepto de cultura suele asociarse exclusivamente a los contenidos que vienen a encuadrarse dentro de las humanidades. Sin embargo, esta visión de la cultura es coja y sólo se concibe globalmente cuando su dominio abarca no sólo la dimensión de pensamiento que clásicamente se ha llamado pensamiento humanístico sino que incluye la ciencia más experimental. Incluso esta perspectiva más compleja se hace más necesaria al comprobar que, a lo largo de la historia, los avances de la ciencia experimental han espoleado a la cultura humanística en su desarrollo.

Si nos posicionamos dentro de esta visión unitaria de la cultura, podemos argumentar que el Centro de Investigación del Cáncer (CIC) de Salamanca es un ejemplo de cultura, en concreto, de cultura científica.

Desde que se comenzó a concebir la idea de construir un instituto de investigación oncológica en Salamanca la característica que lo vertebró y justifica su existencia fue la de propiciar la comunicación fluida entre los científicos con el objeto de catalizar los resultados de su investigación, que previamente se venían desarrollando de un modo más disperso, por carecer de un edificio que los agrupara, en la Universidad de Salamanca ${ }^{1}$.

Este espíritu se capta no sólo al observar el quehacer de sus investigadores, que organizan cada semana un seminario interno y otro externo para comunicar a la comunidad los resultados de su investi- 
gación, sino también en el diseño del propio edificio. Los laboratorios en lugar de estar entre cuatro paredes opacas, están comunicados unos con otros con paredes y puertas de cristal.

Esta concepción no es completamente original, el CIC responde al paradigma de los Comprehensive Cancer Center de Estados Unidos. Este es un modelo restrictivo - menos de cuarenta reconocidos en EE.UU.-, pero que ha demostrado ser el más efectivo a la hora de obtener los mejores resultados prácticos en investigación oncológica. Para ello cumple el requisito - el CIC es el único centro en España con estas características - de desarrollar investigación puntera - evaluada externamente- de tres tipos: básica, clínica y aplicada. De tal suerte, el CIC pretende favorecer el trasvase en sendas direcciones de información entre la ciencia biomédica básica y la aplicada, para fomentar la sinergia de los tres tipos de investigación y en consecuencia mejorar la productividad. A través de esta organización el CIC procura servir de semillero para la creación de riqueza y servicios que reviertan en el desarrollo social y el desarrollo económico. La conexión con la sociedad es uno de sus objetivos prioritarios.

Esta fue una de las razones que provocó la necesidad de crear dentro del CIC un departamento de Comunicación y Marketing. Si los resultados de su investigación no se entendieran como un proceso de cultura científica, la dinámica interna de sus investigadores hacer ciencia y comunicarla en los papers, seminarios y congresos - posiblemente no demandaría este servicio. En cambio, conscientes de este concepto global que constituye la investigación oncológica, se pusieron los medios para transmitir los resultados de la investigación a la sociedad. De tal suerte el Departamento de Comunicación y Marketing es el nexo de unión entre la sociedad y la ciencia, desde él se canaliza la demanda que hace aquélla a ésta y viceversa. Uno de los aspectos cruciales de este departamento es la transmisión de la información generada en el CIC mediante la divulgación científica.

Por sí misma resulta meritoria la iniciativa tomada por los propios investigadores y el esfuerzo que están realizando para acercar la ciencia a la sociedad, aunque lejos de todo triunfalismo dentro del CIC somos conscientes de que queda mucho por hacer y mejorar. Por esta razón, a continuación se expondrán las características esenciales de la divulgación científica para poder perfilar cómo debería ser tal divulgación cuando se tratan aspectos sobre el cáncer ${ }^{2}$ y en consecuencia mejorar la relación entre la investigación oncológica y la sociedad, aspecto éste decisivo de la cultura científica. 


\section{La divulgación científica es imprescindible para establecer el vínculo entre la sociedad y la ciencia}

Se puede apelar a varias razones para justificar la divulgación de la biomedicina, aunque dos de ellas tienen un peso especial y no deben pasarse por alto. La mayor parte de la financiación de la investigación de la ciencia proviene de fondos públicos y por ende la sociedad tiene derecho a saber en qué se está utilizando este dinero, se debe rendir cuentas a quienes pagan. Otro aspecto no menos importante es comunicar los resultados obtenidos de la investigación. En el caso de la información generada por la biomedicina o la oncología, la sociedad muestra una mayor sensibilidad respecto a otras temáticas de la ciencia y por tanto es deseable transmitir cuáles son las distintas orientaciones y los frutos de este ámbito científico.

Sin embargo, ¿en quién debe recaer esta responsabilidad? ¿en los científicos? ¿en los periodistas?

La ciencia no necesita al periodismo científico para su desarrollo, es más, se tiene que hacer y se hace independientemente de la divulgación. De hecho, el método de divulgación de la ciencia son las revistas científicas especializadas. Aunque sí cabe matizar que el científico no sólo hace ciencia sino que también trabaja con becarios en su laboratorio a los que tiene que formar o parte de su jornada laboral transcurre impartiendo clases en la Universidad. En estos ejemplos el investigador no está produciendo ciencia, sino que está divulgando a un grupo selecto. Todos los científicos divulgan, aunque otra cuestión bien distinta es divulgar a la masa. El periodismo científico, en cambio, es la técnica que nbs permite comunicar lo que los científicos hacen a los que desconocen estos contenidos, es decir, a la sociedad no especializada en el tema expuesto. El periodismo científico es una especialidad del periodismo y no tiene más vocación que la de mostrar la realidad científico-tecnológica a quienes no logran alcanzarla en todas sus facetas. $\mathrm{Ni}$ todos los científicos ni todos los periodistas están preparados para divulgar ciencia. El periodismo científico debe llevarlo a cabo quien lo haga bien. No importa si su formación es científica o periodística. Si el científico conoce las técnicas de divulgación a través de los medios, escribe bien y habla bien, puede divulgar el tema en el que está especializado. Si el periodista, aunque no tenga una formación científica, sabe aproximarse al mundo de la ciencia, comprenderlo para posteriormente traducirlo al lenguaje llano de la gente que no sabe, también puede divulgar. 
En última instancia, lo importante es que la transmisión del mensaje sea de manera que todo el mundo lo entienda pero que a su vez no traicione su origen. Por tanto, no es tan trascendental qué formación se tenga, sino las aptitudes desarrolladas por el divulgador. Para divulgar a la sociedad hay que valer, se debe transmitir el mensaje con un contenido inteligible y además nunca debe faltar la fidelidad de la fuente fiable. Ésta se halla tanto en las revistas científicas especializadas, como en los propios científicos. En resumen, la fuente ha de ser fiable, la transmisión del mensaje debe ser clara y rigurosa la información debe ser ponderada y objetiva y debe consultarse realmente al investigador portavoz del grupo de investigación que la ha generado - y su contenido debe ser aquel que muestre los resultados de la investigación. A menudo parte de la investigación no es susceptible de ser divulgada. Se debe hablar de resultados maduros, pues de esta manera se respetan las reglas del juego de la ciencia que sólo saca los papers cuando el contenido puede ser transmitido a la comunidad científica. No hay nada más contraproducente que el investigador, cuyo nombre aparece vinculado a la noticia, desapruebe su contenido, pues con una alta probabilidad esta información no es lo suficientemente rigurosa y en consecuencia en lugar de informar se está desinformado a la sociedad, objetivo contrario al perseguido.

La divulgación biomédica debe tener en consideración otro factor nada desdeñable. En esta área se está avanzando muy deprisa y a su vez está teniendo mucha repercusión en los medios de comunicación pues se supone que en el futuro sus avances van a afectar considerablemente al mundo cotidiano, en aspectos tan próximos como son la salud y el bienestar social. Sin embargo, estas áreas son difíciles de explicar porque atañen a conceptos que la gente no llega a comprender completamente. Se supone que la genética influirá en la salud, pero para explicarla hay que aludir a los genes, a la célula, a su núcleo o al DNA. La dificultad de esta empresa radica en trascender lo que la gente puede entender, mediante un mensaje correcto, de lo que los científicos saben.

\section{Los problemas de la divulgación}

Los divulgadores deben tener un código siempre presente: la ciencia es una institución seria y la medicina aporta información relacionada con la salud de los pacientes. No se puede jugar con una información tan delicada y sensible para la sociedad. Hoy en día se está cayendo 
en la desinformación y se da una imagen de la medicina sin control. Hay que divulgar los trabajos concluidos que se realizan en la investigación, pero sin vulgarizarla, para evitar de esta suerte consecuencias sumamente nocivas para la sociedad.

El consumo incontrolado de antibióticos está generando una resistencia a los mismos que va a traernos muchos quebraderos de cabeza en pocos años. La vulgarización de la medicina está comenzando a dar sus frutos.

No sólo se está desinformando, sino que además se está educando mal a la sociedad. El colesterol, las sardinas hoy son buenas y mañana son malas. Se puede decir que beber es malo, pero al día siguiente los medios se hacen eco de que beber un vaso de vino es bueno. Se está llegando al límite de la justificación de todo. En la consulta el médico puede aconsejar al paciente que no beba alcohol y éste quizá le reproche que ha oído que beber es bueno y que en realidad él sólo bebe una caña, un carajillo y uno vaso de vino al día. En definitiva, se están justificando conductas que no permiten prevenir enfermedades. Este hecho se constata también en el campo de la oncología. Como consecuencia de esta avalancha de información caótica, alguien puede argüir que el tabaco puede producir cáncer de pulmón aunque también previene el parkinson. Se están dando razones sin solidez pero que la persona que tiene por ejemplo dependencia del tabaco los coge como válidos. Esta es una conducta completamente equivocada desde el punto de vista sanitario. Da la sensación de que con tanto consejo contradictorio la persona puede poner en una balanza los efectos beneficiosos y perjudiciales del tabaco y que sea ella misma la que elija, lo cual es un gran sin sentido. Toda la comunidad científica afirma que el tabaco es una droga muy nociva para la salud y por consiguiente la opción más saludable sin duda alguna es dejar de fumar.

La divulgación correcta, dada esta situación, es más necesaria que nunca. Se está llegando al extremo en que la información que recibe la población es tan contradictoria que los propios científicos están perdiendo prestigio. 'Nos guste o no, la medicina tiene un componente mágico. La sociedad necesita un componente mágico y en nuestra civilización el mago siempre fue el médico. Había partes que la sociedad no entendía, pero el médico sí. En el pasado se tenía la imagen de que el médico era el señor que lo sabía todo, era capaz de solucionar el problema y cuando no podía resolverlo se debía a que no había solución. En cambio, hoy por hoy el médico es un señor funcionario que te tiene que curar y si no te cura es un incompetente y si no sabe la respuesta es un ignorante. Si fulanito va al médico porque 
padece un cáncer de pulmón y tiene que radiarse, si por cualquier circunstancia la vecina le comenta que a su marido en lugar de radiarlo le dieron quimioterapia, este señor posiblemente ya no se fíe del médico. Asimismo quizá sospeche al comprobar que no es tratado con terapia génica, cuando ha leído u oído en los medios que el último avance en medicina es la terapia génica y lógicamente quiere ser tratado con ella. Nadie dice en los medios, o pocos, que la terapia génica es una alternativa que funciona en ratones, pero que aún no existe ningún ensayo de terapia génica válido. Las células madre es otro tema de actualidad en los medios y aún no se ha curado a nadie con ellas.

Cuando se lanza una noticia que promete también es imprescindible informar de que ese experimento que prometía tanto, pasado un tiempo, se comprobó que no funcionó. Si se publican los positivos contrastados igualmente se deben publicar en prensa los negativos, como ocurre en ciencia. $\mathrm{Y}$ esto en el periodismo no es ninguna constante.

La divulgación científica se debe hacer a nivel general y dejar de crear falsas expectativas a la sociedad. En ocasiones, sobre todo delante de las cámaras de televisión, los científicos dan la imagen de que saben todo y lo controlan todo. Los medios publican que se conoce el genoma y esto va a permitir curar las enfermedades genéticas pero no han publicado que aunque se conoce el genoma, un gen produce más de una proteína y que puede estar mutado en distintos sitios. Es decir, que no conocemos nada. Los científicos están empezando a entender cómo funciona el genoma, pero eso no lo dice la prensa. Y la gente como lo que cree es conocen el genoma, que a partir de ahora van a curar todo. Nadie les ha informado que una cosa es el genoma, otra las proteínas y otra la reproducción de la célula. Eso es divulgar. Exponer que se está estudiando el genoma humano y con ello sabemos «x» pero no sabemos «y» ni "Z» y nos va a llevar muchos años conocer tanto «y» como «Z». Los científicos especializados en el genoma son conscientes del camino que aún queda por recorrer, pero los medios no están dando esta información y en consecuencia el mensaje llega sesgado a la sociedad.

Probablemente esta problemática se superaría si la financiación destinada a la investigación llegara independientemente de que el investigador sea más o menos popular. Con frecuencia los propios científicos asumen esta dinámica de divulgar todo lo posible por la presión que tienen de obtener financiación para poder seguir investigando. La ciencia se está enfrentando a este problema porque el trabajo desarrollado está dependiendo de los fondos privados y éstos se consiguen mediante el marketing, al obtener un resultado en una investigación determinada hay que divulgarlo. 


\section{El Centro de Investigación del Cáncer...}

Esta actitud se puede observar en ocasiones incluso en las revistas científicas especializadas, a éstas con frecuencia les va interesando dar prioridad al titular. Se está produciendo un movimiento en el que uno de los criterios es el impacto que se obtiene de un artículo. A partir de un editorial se filtra la información, que a su vez acaba saliendo en los medios y al final la revista se conoce más. Los intereses económicos subyacen en esta realidad. Cuanto más popular es una revista, más vende, cuanto más vende, más impacto tiene, cuanto más impacto tiene, más originales recibe y cuantos más originales recibe, más puede publicar. Aunque no es deseable esta situación, las consecuencias no son tan nocivas como el titular injustificado del periodismo. Todo lo publicado en las revistas científicas pasa el examen de un comité de expertos, el titular de estas revistas no reza «vamos a curar el cáncer» y además estas revistas se leen con espíritu crítico que caracteriza el quehacer científico, pues normalmente sólo son leídas por este colectivo y tras la revisión del artículo encabezado con un gran titular, el investigador inferirá si vale o no la pena las conclusiones del artículo, dado que tiene una formación que se lo permite. Mientras que en prensa el lector no suele pasar más allá del titular y cuando se lee la noticia en su totalidad, normalmente no se hace con aquél espíritu crítico, pues no se cuenta con la formación para poder concluir si aquella noticia tiene rigor o no. Casi se convierte la lectura y su asimilación en una cuestión de creencia.

En España se ha venido utilizando el titular para que después la letra pequeña venga a decir luego otra cosa. En este sentido tanto a los científicos como a los divulgadores nos tenemos que exigir ser realistas, explicar realmente el significado de una noticia científica, aparte del optimismo que puede emanar del avance de la investigación, hay que indicar cuál es el verdadero alcance empleando un lenguaje que entienda la sociedad.

Por desgracia con demasiada frecuencia se crea ilusión en el enfermo con los titulares y se prometen cosas que no se van a cumplir o si se van a cumplir, será a muy largo plazo. En prensa se puede encontrar un titular como «se ha creado un tratamiento para una aproximación terapéutica para el tratamiento de cáncer de estómago». A la gente que no tiene un cáncer de estómago la noticia no le interesa mucho. Pero si se tiene un familiar con este tipo de cáncer, la persona que ha recibido esta información le interesa que al enfermo se le puedan aplicar ese tratamiento, lo cual va a ser imposible en cinco o diez años. Ahí se están creando unas falsas expectativas. Se está dando el tipo de mensaje repetitivo de «esto va a ser una cosa muy buena 
para el tratamiento del cáncer». Desde hace años se repite que «los investigadores de la entidad $\mathrm{x}$ han descubierto un nuevo remedio para el cáncer y». Y cuando se empieza a leer la noticia con detalle se dice en las líneas posteriores que el estudio se ha realizado con células in vitro en ratones. Cuando se dice que este tratamiento se podría aplicar a humanos y, en realidad, casi nunca se aplica. Se crea una falsa expectativa tremenda cuando tan sólo existe un gran titular cogido con alfileres. Este es un esfuerzo que deben hacer los investigadores de no dar falsas esperanzas.

$\mathrm{Al}$ final se recurre al típico tratamiento consolidado desde hace quince años y que ha sido modificado para su mejora poco a poco. Efectivamente, los médicos no dejarán de dar quimioterapia de la noche a la mañana a sus pacientes oncológicos para poner en práctica otro tratamiento novedoso, porque si llevaran a cabo esta sustitución, a lo mejor en lugar de curar se matarían al enfermo por otra vía. En esta información hay que ser tremendamente cautos, insisto, no podemos crear falsas expectativas en la población. En la actualidad en las consultas se va notando que la gente cada vez lee más y navega más por Internet y solicitan que se les aplique la medicina que salió ayer en la televisión, porque decían que iba a curar el cáncer que la persona padece. Quizá el médico no haya visto la televisión el día anterior, y no sabe de qué medicina le están hablando o quizá lo que no se explicó en la noticia que vio el paciente que esa medicina se ha probado en un ratón, pero no en un humano, y que este medicamento todavía no ha pasado todos los requisitos ni ha sido lo suficientemente investigado para garantizar que al ser administrado a personas se obtenga una mejora o curación. Es posible que en ratones sane, pero que en personas mate.

Otro de los inconvenientes al que nos enfrentamos a la hora de divulgar noticias es que hay detalles en la propia investigación que en ocasiones el propio investigador no entiende. Existen muchos mecanismos dentro del experimento desarrollado en una investigación que no se comprenden totalmente. Se aplica un método para obtener un resultado y muchas veces se desconocen los procesos intermedios. Toda investigación parte de una hipótesis clara y se puede obtener un resultado exitoso, aunque se hayan producido procesos intermedios poco conocidos en su totalidad. Por ejemplo, al intentar meter un fragmento de DNA dentro de un plásmido ${ }^{3}$, la mayoría de las veces se realiza sin problemas, pero en ocasiones no se puede y en este caso se desconoce la causa de este impedimento. Hay aspectos, como el recién expuesto, de la investigación que no se puede divulgar. Se puede 
dar la circunstancia de que el científico no conozca las causas últimas de este hecho y por otra es una tarea imposible que el científico pueda comunicar la información correctamente al divulgador para que éste a su vez entienda el proceso explicado, del que apenas conoce de cerca, y le permita plasmarlo en una noticia que leerá u oirá un público que tampoco tiene una formación especializada en el contenido divulgado. Esta es por tanto otra de las dificultades a las que se enfrenta el periodismo científico, a menudo intenta divulgar lo indivulgable.

Dentro de esta imagen falseada que se está dando de la realidad no todos los aspectos tienen matices tan pesimistas como los expuestos hasta el momento. Para finalizar este apartado analizaremos un último punto algo más alentador, parte de la situación que estamos viviendo hoy en día en España.

Cuando se comunica realmente resultados importantes no en cuanto a un fármaco prometedor, sino en cuanto a tratamiento, generalmente lo que se suele comunicar a nivel de prensa y televisión son estudios en el extranjero. Este hecho hace que las personas que padecen un cáncer tengan la visión de que aquí no se trata el cáncer o que se trata mal o no tan bien como en EE.UU. o como en otros países de Europa y esto no siempre es cierto.

El servicio de hematología del Hospital Clínico Universitario de Salamanca ha tenido la experiencia de personas que han ido a hospitales prestigiosos de Estados Unidos, famosos por atender a pacientes que proceden de otros países, y que nada más llegar allí les han preguntado por qué acudían a ellos cuando les estaban tratando en Salamanca. Estos pacientes han regresado y se ha continuado el tratamiento en Salamanca.

Esta es una cuestión que no se está transmitiendo. En este momento en España se están haciendo unos estudios tan buenos como en el resto de países y que están siguiendo el tratamiento que han impuesto centros prestigiosos estadounidenses. No sólo en Salamanca sino también en otros centros se están haciendo estudios corporativos. Por citar un ejemplo, en el tratamiento especial de un tipo de leucemia mieloblástica, que es la leucemia mielocítica aguda, el grupo español de tratamiento de la leucemia mielocítica aguda tiene los mejores resultados del mundo, pero la sociedad no lo sabe. Este es un ejemplo claro, pero hay muchos más. También es cierto que al menos si no cambia mucho el panorama, siempre va a haber un diferencial en cuanto al tiempo entre Estados Unidos, Europa y España, pero esta distancia cada vez es más corta. Antes se aplicaban tratamientos que 
se habían estado estudiando en EE.UU. diez años antes. Ahora el diferencial es de unos meses o un año, así que la diferencia no es tanta y por consiguiente tampoco mejora sustancialmente el tratamiento en Estados Unidos. Incluso con frecuencia cuando una persona necesita un tratamiento oncológico en EE.UU. le van a someter a un protocolo que muchas veces va a ser experimental, con lo cual en estos casos a menudo va a estar en los límites de lo que nosotros consideramos ético en un momento dado.

Los familiares o el propio enfermo, comprensiblemente, quieren poner los mejores medios para tratar al paciente y cuando se le informa que la ventaja de tratarle en España es que el tratamiento es gratuito y el resultado del mismo no es peor, les cuesta entender este hecho. La idea generalizada es que la situación aquí es mala, que el sistema de sanidad es bueno, pero no es para tanto. No hay lista de espera en hematología del Hospital Clínico Universitario de Salamanca, es de un día para otro. Y generalmente en los hospitales son lo suficientemente conscientes de que si se hallan ante un caso en que es urgente trasplantar, por la razón que sea, se ponen todos los medios para agilizar este trámite, hay algunos pacientes que tienen que esperar para el trasplante, pero en su caso es que da igual trasplantar en un mes o en cuatro. En el servicio de oncología de este hospital la espera es de un día o una semana. En ocasiones se puede complicar el día, pero cuando un paciente debe esperar es porque se sabe que el tumor es lo suficientemente lento como para que no pase nada.

En la actualidad el servicio de hematología del Hospital Clínico Universitario de Salamanca está pendiente de empezar y de coordinar a nivel europeo el tratamiento de mieloma. Los resultados del grupo español de mieloma no tienen nada que envidiar al resultado que se puede sacar en el mundo sobre el tratamiento de mieloma. Este hecho no se está comunicando bien a la población. La sociedad tiene la idea de que periódicamente o cada semana en la televisión sale alguien que ha publicado algo generalmente procede de la investigación básica y rara vez de investigación clínica. En consecuencia, se está dando la imagen de que aquí se llevan a cabo muchos estudios básicos pero que no existen investigadores que obtienen resultados más aplicados en el tratamiento del cáncer, cuando en realidad estos resultados no sólo existen sino que además tienen gran calidad. Se debería fomentar la divulgación en los medios de comunicación masivos de este tipo de noticias, que en la actualidad están quedando en la sombra. 


\section{El Centro de Investigación del Cáncer...}

\section{Situación del cáncer que conviene divulgar a la sociedad}

El problema del cáncer es que se está denominando con el mismo concepto general — «cáncer»- a 200 tipos de enfermedades distintas que no tienen nada que ver la una con la otra en absoluto. Probablemente de aquí a unos cincuenta años cuando la gente lo vea con perspectiva histórica se sorprenderá que en nuestros días se una bajo un mismo concepto un cáncer de piel y un cáncer pancreático. No tiene ningún sentido meter a estas enfermedades en el mismo concepto. Es como afirmar «tengo una infección». Cuando todos sabemos que la infección de unas anginas o el sarampión de un niño difiere bastante de una meningitis. Efectivamente, todas son infecciones, pero provocadas por diferentes microorganismos, unos se tratan bien, otros mal, unos tienen antibióticos específicos otros no, unos pueden poner en peligro la vida del enfermo mientras que con otros la inmunidad del enfermo acabará venciendo la enfermedad. Evidentemente se pueden clasificar bajo una misma categoría las infecciones por bacterias, las infecciones por hongos y por virus, pero en el caso del cáncer el campo es mucho más abierto. Normalmente cuando hablamos de cáncer estamos haciendo mención a los cánceres más frecuentes o a los cánceres que tienen peor tipo de tratamiento, sin tener en consideración esta diferencia conceptual.

Hoy por hoy el panorama en el tratamiento del cáncer ha mejorado considerablemente. Hasta ahora lo verdaderamente eficaz, el primer arma terapéutica en los cáncer en general, es la cirugía. En segundo lugar tenemos, y a veces es más eficaz que la cirugía, la quimio-radioterapia, la hormoterapia, terapias combinadas. Los efectos colaterales de la quimioterapia y la radioterapia así como los de la cirugía, con la laparoscopia, se han minimizado. Uno de los objetivos de la cirugía consiste en ser lo más eficaces posible dentro de un tumor determinado con la mínima agresión quirúrgica. $Y$ no siempre hacer una gran intervención, como puede ser seccionar a un hombre por la mitad, es más eficaz que hacer una intervención más pequeña. El ejemplo paradigmático es el cáncer de mama. Hace cuarenta años cualquier intervención de cáncer de mama implicaba quitar la mama y los pectorales. Mientras que ahora en la mayor parte de las intervenciones se conserva la mama y se quita nada más el tumor. Por tanto, la intervención es menor pero igual de eficaz y es combinada con quimioterapia, radioterapia o incluso con hormonoterapia. El desiderátum para el futuro es obtener medicamentos que incidan y destruyan exclusivamente células tumorales y no otras. 
Un hecho evidente, que la sociedad debe conocer, es que la supervivencia de los enfermos de cáncer se está prolongando y esto está ocurriendo en la mayoría de los cánceres. La lucha contra el cáncer no retrocede sino que va hacia delante. Cada vez se erradican con más facilidad más tipos de cáncer. Pero lógicamente la supervivencia va aumentando lentamente a base de aplicar modificaciones de los tratamientos que tenemos previamente. No hay terapias maravillosas que se pueda decir de ellas: «esta es la buena, la que vale».

En este momento asistimos a un período relevante dentro de la hematología con el Glivec - es un ejemplo de fármaco novedoso- que permite en la actualidad el tratamiento más a la carta. Teóricamente sólo mata las células anormales y las mata todas. Pero incluso con este fármaco, que se está aplicando hoy en el tratamiento de leucemia mieloide crónica y en la leucemia linfoblástica aguda, se está constatando que las resistencias al mismo aparecen en tres o cuatro meses en la leucemia linfoblástica aguda, así que las respuestas no duran - como ocurre con las bacterias que se hacen resistentes a los antibióticos. $\mathrm{Y}$ en el tratamiento de la leucemia mieloide crónica no se sabe cuanto durará, se presupone que no va a ser eternamente. Se conjetura que al igual que está habiendo resistencias en las células de la leucemia aguda linfoblástica, habrá resistencias en las células de la leucemia mielode crónica. Los enfermos españoles se tratan igual que en el resto del mundo con este fármaco excepto con una salvedad, el enfermo español no paga un solo euro por él en la seguridad social - el coste ronda los 36.000 euros anuales, unos seis millones de pesetas por paciente -mientras que el enfermo de otras partes del mundo está pagando muchísimo dinero. Este es un gasto importante para el sistema de salud y no se está escatimando medios. Cuando merece la pena tratar a un enfermo con este fármaco se emplea. A pesar de todo los resultados son muy buenos, pero no son extraordinariamente buenos, porque al final el enfermo de la leucemia aguda linfoblástica a causa de las resistencias generadas no se cura con este fármaco. El Glivec es uno de los fármacos más conocidos por la repercusión que ha tenido en los medios de comunicación pero existen otros similares que se están investigando y que son inhibidores de otras vías metabólicas para otra serie de tumores.

Da la sensación que la gente que hace ciencia todo lo que dice es verdad cuando a veces la realidad no es tan exacta a esta imagen. Hay que ser muy cautos a la hora de afirmar que «con el tratamiento «X» te vas a curar», porque la sociedad luego lo demanda, y no les faltaría razón si la información que han recibido fuera completamente 


\section{El Centro de Investigación del Cáncer...}

cierta. No es necesario recurrir a los tratamiento novedosos como el presentado en las líneas anteriores para encontrarnos esta realidad. Cuando los hematólogos tratan a una persona mayor, de unos ochenta años, con leucemia a menudo se tiene que convencer a la familia que no se le puede hacer un transplante de médula. Los familiares posiblemente argumenten que han visto en la televisión que el transplante de médula cura la leucemia y no entienden por qué no se le puede realizar un trasplante de médula a esta persona anciana. A continuación el médico tiene que desmontar que una persona de ochenta años no está en situación de recibir un trasplante de médula porque tendría otras complicaciones que lo matarían. La gente cree que el trasplante de médula cura la leucemia y efectivamente es cierto pero dentro de unas coordenadas, con una determinada edad, etc.

La biomedicina a medida que avanza está mejorando el conocimiento de la biología de los tumores, los tipos de terapéutica que se aplican en un momento determinado en un tipo de tumor. Dependiendo del nombre y apellidos del tumor así se tratará al paciente. El ejemplo más típico es el cáncer de tiroides, el médico tiene que considerar el tipo de cáncer de tiroides y en quién está implantado. Si se trata de un cáncer de tiroides anaplásico en un enfermo de setenta años, el pronóstico no es bueno. Mientras que un cáncer de tiroides en una niña de catorce años tiene un buen pronóstico, pues esa niña puede sobrevivir tanto como su amiga que está sana. La mayor parte de los cáncer de tiroides se curan. Efectivamente, hay que hablar de qué tipo de cáncer se va a tratar y en qué paciente se halla.

Esta realidad debe ser divulgada para evitar estos malos entendidos que se crean en las consultas, causados por la mala información que se está dando sobre los tipos de cáncer y sus tratamientos. Una de las consecuencias más preocupantes de esta situación es que, como ya se ha expuesto, el médico ha dejado de ser una figura respetada a ser una figura denostada. Este hecho no sería relevante si una parte de la capacidad de curación del médico dependiera exclusivamente de la ciencia y no el arte. La parte de arte de la medicina consiste en que el paciente tenga confianza en el doctor. Si el éxito de curación depende en cierta medida de la confianza que el enfermo tenga hacia el médico y los pacientes están perdiéndola por la gran desinformación que recibe la sociedad, poco favor estamos haciendo a la medicina. Si el paciente está a la defensiva con el médico, no se da una transferencia, tan fundamental en medicina para la curación del enfermo, entre ambos. Si no hay confianza en el médico ya puede intentar 
hacer esta transferencia que es imposible, pues aquél estará pensando a ver cómo le engaña, cómo le atiborra de píldoras.

En último lugar conviene aludir a otro gran problema al que se está enfrentando la oncología causado por dos grandes expectativas que se están transmitiendo en los medios: la prevención y la curación del cáncer. Por una parte, se tiene concebida la idea de que si una persona sigue los consejos de llevar una vida saludable evitará padecer cáncer, lo cual es cierto, pero con matices. Hay personas que no beben alcohol, ni fuman y se han sometido a revisiones médicas anuales, pero que desarrollan algún tipo de cáncer. En este caso estas personas suelen exteriorizar, injustamente, sentimientos de culpabilidad porque creen que en algo han fallado. Por otra parte, se tiene la imagen de que el enfermo oncológico si no lucha ni se preocupa, las cosas no van a salir bien. Cuando en realidad, hoy en día se está curando el 50 por ciento de los cánceres. Dependiendo del tumor en algunos casos el éxito llega al 80 por ciento, mientras que en otros sólo alcanza el 10 por ciento. Esto significa que no todo el mundo se cura. No se quiere asumir que la gente se muere, sobre todo aquella generación de personas adultas sin fuertes convicciones religiosas, pues la población más joven nunca piensa que se va a morir. Ojalá pudiera ser, pero la realidad es que no a todo el mundo se le puede curar, independientemente de la actitud que tenga.

En estas líneas se ha esbozado las características del crudo contexto actual que no conviene olvidar a la hora de comunicar información sobre el cáncer, pues el optimismo exagerado que puede acompañar una noticia difumina este hecho hasta llegar a distorsionar, sin querer, la realidad. Pecar de imprudentes tiene consecuencias tan negativas como las que se han desarrollado en este escrito. Conviene evitar gastar tanta tinta en divulgar noticias que con el paso del tiempo nadie recordará porque se comprobó que no eran tan relevantes en la investigación.

Sin duda alguna, todos los sectores implicados en esta empresa de acercar la ciencia a la sociedad deben esforzarse en esta tarea. El investigador debe tratar de transmitir claramente el mensaje al divulgador. Muchas veces al científico le cuesta explicar lo que hace, y cuando lo intenta normalmente simplifica demasiado las cosas o las complica, por dar por supuesto mucha terminología. Para el investigador básico no es fácil transmitir que la ciencia básica es la que puede dar soluciones transcendentales, a pesar de que parecen estar tan alejadas de una aplicación, para proseguir con la investigación. Este mensaje urge ser comunicado a la sociedad. Cada vez en España en 


\section{El Centro de Investigación del Cáncer...}

lugar de multiplicar se está reduciendo drásticamente el presupuesto público para la investigación básica - no hay más que analizar las cifras del Plan General del Conocimiento que en dos años ha recortado su presupuesto para investigación básica a la mitad ${ }^{4}$ - seguramente no se sabe valorar la utilidad de este conocimiento que sustenta a la investigación pues sus porcentajes de «utilidad» para la humanidad siempre han sido muy bajos, pero no por ello menos importantes la penicilina no se hubiera descubierto sin la investigación básica. Con estos recortes, los jóvenes investigadores tienen las puertas cerradas a la investigación básica. $\mathrm{Y}$ en tanto en cuanto se socave la financiación para la investigación básica se está minando el futuro de la ciencia de este país. Las investigaciones aplicadas dan de sí hasta cierto punto, y cuando se llegue a este límite, se tendrá que buscar lo que se ha hecho en otros países en investigación básica. Como siempre.

$\mathrm{El}$ investigador aplicado debe exponer con especial cuidado las noticias dado que esta investigación está muy próxima al ciudadano, más que los resultados de la investigación básica. Muchos avances a nivel de laboratorio están a un paso de la clínica aunque muchas veces este paso no se llega a dar. $\mathrm{Y}$ en este sentido se tiene que explicar muy claramente el contexto en que se ha hecho la investigación y de las expectativas que puede dar. Sin echar las campanas al vuelo y sin lo contrario.

El divulgador debe transmitir con mucha cautela y buscando el titular apropiado todas las noticias relacionadas con la salud. Hay que ser transparente en la información que se da a la sociedad, ya sean de trabajos concluidos como de datos sobre en qué se ha invertido el dinero público en la investigación. Evidentemente la tarea no es sencilla y aún queda mucho por hacer y mejorar. Se deben explorar no sólo los campos de la divulgación científica relacionada con los medios de comunicación. El desarrollo de la cultura científica está demandando otras vías complementarias a aquélla, como es la comunicación directa entre la sociedad y la ciencia mediante conferencias, jornadas de puertas abiertas y otro tipo de actividades. El Centro de Investigación del Cáncer de Salamanca es consciente de esta necesidad que día a día intenta cubrir. Queda mucho por hacer y el trabajo no ha hecho más que comenzar.

\section{Notas}

1 El proyecto inicial de construir el CIC tuvo un carácter local y regional, posteriormente su dimensión fue nacional pues el Consejo Superior de Investigaciones 
Científicas (CSIC) mostró su interés por el mismo, creando el Instituto Mixto de Biología Molecular y Celular del Cáncer (IBMCC) del CIC. Mediante el IBMCC se permite el acceso de investigadores y científicos especializados de todo el territorio nacional al CIC. Las consejerías de Sanidad y de Educación de la Junta de Castilla y León han asumido una participación directa en el CIC a través de su presencia en el Patronato de la Fundación para la Investigación del Cáncer de la Universidad de Salamanca (FICUS). Efectivamente, la estructura organizativa investigadora del CIC incluye un Instituto Universitario (LRU), un Instituto Mixto (CSIC-Universidad de Salamanca) y un Centro Sanitario ( ${ }^{\circ}$ Registro 5-14-0001) que engloba las Unidades y actividades relacionadas con el Sistema regional y nacional de Salud.

2 Este artículo no hubiese podido ser redactado sin la colaboración de todos investigadores principales del Centro de Investigación del Cáncer. Sus valiosos argumentos y críticas han dado forma a este escrito.

3 Plásmido es cualquier tipo de inclusión intracelular que se considera tiene una función genética, especialmente una molécula de ADN procedente del cromosoma bacteriano que determina rasgos no fundamentales para la viabilidad del organismo, aunque de algún modo cambia la capacidad del organismo para adaptarse. (Diccionario Mosby: Medicina, enfermería y ciencias de la salud, de la editorial Harcourt).

4 Este hecho está afectando también a la microbiología básica. A la industria le interesa la biotecnología, pero no le interesa ni cuantos microorganismos hay en el mundo, ni qué tipo de metabolismos hacen, cuando precisamente en el reconocimiento de estos metabolismos están las aplicaciones biotecnológicas para los diez o quince años próximos. Y sólo conocemos el $1 \%$ de los microorganismos que hay en el planeta. Si no se invierte en investigación básica mal impulso se le está dando a la ciencia en general. 